\title{
A Comparative Study of Scrotal Pathologies by Ultrasound and Their Correlation with CT and MRI
}

Thakur Hari Dayal Singh ${ }^{1}$, P Keerthi Bharati ${ }^{2}$

1. Associate Professor, Department of Radiology, Prathima Institute of Medical Sciences, Naganoor, Karimnagar.

2. Assistant Professor, Department of Radiology, Prathima Institute of Medical Sciences, Naganoor, Karimnagar.

Address for correspondence:Dr. P Keerthi Bharati, Assistant Professor, Department of Radiology, Prathima Institute of Medical Sciences, Naganoor, Karimnagar, Telangana, India. Email: drkeerthipendyala@gmail.com

Date of Receiving: 17-01-2021

Date of peer review 7-02-2021

Date of acceptance: 24-02-2021

DOI:10.47799/pimr.0901.11

\section{ABSTRACT:}

Background: The scrotum is a readily examinable structure clinically in normal conditions. However, in cases of swelling and tenderness, its clinical examination alone may not reveal any significant information. Therefore, imaging techniques such as ultrasound including CT and MRI may be required in cases. We in the current study tried to evaluate the role of ultrasound, $\mathrm{CT}$, and MRI in the evaluation of scrotal pathologies.

Methods: All the cases of scrotal pathologies referred from the Departments of Urology and General Surgery, were included in the study. All the patients were studied using Highfrequency real-time grayscale ultrasonography and Doppler. Before subjecting the patients for ultrasound examination, patient details, detailed clinical history was obtained along with thorough physical examination. The color Doppler sonography was routinely performed in all these patients. Subsequently, these cases were followed up and correlated with histopathology report, fine needle aspiration cytology results, surgical findings, response to treatment.

Results: Out of $n=50$ cases studied most of the casesClinically presented with a combination of multiple symptoms wasscrotal swelling, as in $n=18$ cases (36\%). Out of which $n=30(60 \%)$ were unilateral and $n=20(40 \%)$ werebilateral.Combination of pain, swelling, and fever in four cases (8\%). The $n=30$ unilateral swelling showed $n=14$ cases of right-side involvement and $n=16$ cases of left-side involvement. Of $n=5$ cases of congenital anomaly associated with the descent of testes, $n=2$ cases were referred with clinical suspicion of incompletely descended testes, which were clinically palpable. $4 \%$ cases of scrotal and testicular trauma were detected. Among non-neoplastic scrotal swellings, hydrocele is the commonest pathology noted in $n=9$ cases. Epididymal cyst in $n=2$ cases, varicocele in $n=6$ cases.

Conclusion:

ultrasonography is best for the demonstration of morphological changes due to acute scrotal inflammation. The color doppler sonography can accurately differentiate between testicular ischemia and torsion from acute inflammatory diseases. High-frequency ultrasonography with Doppler is highly sensitive in demonstrating the varicoceles. MRI provides better delineation of borders, cystic components, and tissue signal intensities of the testicular masses. CT is the imaging modality of choice for detecting metastatic deposits

Keywords: Scrotal Pathologies, Ultrasound, CT, MRI Introduction

The scrotum is a musculo-fascial sac containing the testes,epididymis, and the lower part of the spermatic cord. The scrotum is divided into right and left parts by a ridge or median raphe. The raphe is continued to the undersurface of the penis and posteriorly along the midline to the perineum to the anus. The clinical examination of these structures is very easy especially in absence of pathology. Most of the disease of scrotum causes swellings and tenderness which are difficult to diagnose based on physical examination alone. There is a greater difficulty to decide the swelling is from intra-testicular 
or extra testicular structures. Acute pathological conditions such as testicular torsion and acute epididymal-orchitis hamper the diagnosis due to overlapping clinical features. ${ }^{[1]}$ Besides, the normal examination may overlook significant pathology, and physical signs elicited may be improperly interpreted. Till the last part of the 20thcentury, the evaluation of scrotal contents was confined to palpation, trans-illumination, supplemented by investigativemodalities such as thermography and venography. ${ }^{[2]}$ The present-day diagnostic armamentarium includeshigh-frequency greyscale Ultrasonography, Doppler studies, Magnetic Resonance Imaging, in addition to radioisotope studies and testicular angiography.The advantages of ultrasonography in the evaluation ofscrotal diseases are because it is non-invasive, easy reproducibility, rapid evaluation with real-time examination capability, easyavailability, economical, and the lack of radiation. Computedtomography has the disadvantage of ionizing radiation to thegonads, requirement for contrast media, and is a relativelyexpensive modality. Magnetic Resonance Imaging (MRI)is also expensive and not readily available, even though itprovides improved cross-sectional information. Therefore,USG is the undisputed first-choice investigation for scrotalpathologies. ${ }^{[3]}$ We in the current study tried to evaluate the usefulness of high-frequency greyscale ultrasonography and color doppler study in pathologies of the scrotum with $\mathrm{CT}$ and MRI correlation if required.

\section{Materials and Methods}

This cross-sectional study was performed in the Department of Radiology, Prathima Institute of Medical Sciences, Naganoor, Karimnagar. Institutional Ethical committee permission was obtained for the study. Written consent was obtained from all the participants of the study in a designated format. All the cases of scrotal pathologies referred from the Departments of Urology and General Surgery were included in the study. All the patients were studied using High-frequency real-time grayscale ultrasonography and Doppler. Before subjecting the patients for ultrasound examination, patient details, detailed clinical history was obtained along with thorough physical examination. The color Doppler sonography was routinely performed in all these patients. Subsequently, these cases were followed up and correlated with histopathology report, fine needle aspiration cytology results, surgical findings, response to treatment. Follow-up scans were done in selected cases when clinically indicated. An abdominal ultrasound scan was done in conjunction with scrotal scans in cases of testicular malignancy to look for associated pathology, in cases of varicoceles to look for any cause of testicular vein obstruction. Conventional radiography was done wherever indicated. In this studyusing High-resolution real-time grayscale ultrasonographyand Doppler study of the scrotum was carried out using 7.5 to 10
$\mathrm{MHz}$ linear transducers, abdominal ultrasonography was done using 3.5 to $5.0 \mathrm{MHz}$ convex curved array transducer of PHILIPS HD7 ULTRASOUND SYSTEM andCT:TOSHIBA Auklet single-slice spiral CT, MRI: GE Sigma EXCITE 0.2T open magnet.Scanning technique:Scanning was routinely performed in the supine position, after elevating the scrotum using a towel draped over thighs, and the penis is placed on the patient's abdomen and covered with a towel. Both hemiscrotum was examined in transverse, sagittal, and oblique planes. Scanning was also done with the patient position upright and during performing Valsalva maneuver. Additional scans of the spermatic cord in the region of the scrotal neck and inguinal canal region were obtained in special circumstances: Undescended testis, encysted hydrocele of cord, and varicocele.During the ultrasound scan, on a routine basis, all parameters were evaluated. All the records were entered in MS Excel and analyzed by SPSS version 19 on windows format for calculation of descriptive parameters.

\section{Results}

A total of $n=50$ cases were examined from various age groups out of which $n=5$ cases were from age group $11-20$ years, $n=13$ were from age group $21-30$ years, $n=12$ cases were from age group $31-40$ years, $n=10$ cases from age group $41-50$ years and $n=5$ cases each from $51-60$ years and $61-$ 70 years respectively. The mean age group was 35.5 years.

Table 2: Clinical Presentation and frequency of Symptoms

\begin{tabular}{|l|c|c|}
\hline Symptoms & Frequency & Percentage \\
\hline Pain and Scrotal Swelling & 7 & 14 \\
\hline Pain, Swelling, and Fever & 6 & 12 \\
\hline Scrotal Swelling & 18 & 36 \\
\hline Unilateral Swelling & 13 & 26 \\
\hline Bilateral Swelling & 5 & 10 \\
\hline Pain in scrotum & & \\
\hline Acute onset & 6 & 12 \\
\hline Chronic onset & 8 & 16 \\
\hline Infertility & 2 & 4 \\
\hline Trauma & 1 & 2 \\
\hline Dysuria & 2 & 4 \\
\hline Discharging wound on the scrotal skin & 1 & 2 \\
\hline Pain abdomen & 4 & 4 \\
\hline
\end{tabular}


Various clinical presentations as depicted in table-2Most of the cases are Clinically presented with a combination of multiple symptoms.Combination: Commonest clinical presentation wasscrotal swelling, as in $n=18$ cases (36\%).Out of which $n=30(60 \%)$ were unilateral and $n=20(40 \%)$ werebilateral.Combination of pain, swelling, and fever in four cases $(8 \%)$. The $n=30$ unilateral swelling showed $n=14$ cases of right-side involvement and $n=16$ cases of left-side involvement. The different pathologies detected in the cases have been given in table 3 . Of $n=5$ cases of congenital anomaly associated with the descent of testes, $n=2$ cases were referred with clinical suspicion of incompletely descended testes, which were clinically palpable. All were unilateral in the presentation. Age of presentation varied from 2 Years to 26 years, with a median age of 3 years. The size of undescended testes was found to be smaller in cases, which presented clinically in later stages.In the present study, $4 \%$ of cases of scrotal and testicular trauma were detected. The etiology of trauma included sports injury in 1 case, road traffic accident in 1 case. Both are unilateral, out of $n=1$ cases on the right side and $n=1$ cases were on the left side.Among non-neoplastic scrotal swellings, hydrocele is the commonest pathology noted in $n=9$ cases. Epididymal cyst in $n=2$ cases, varicocele in $n=6$ cases.
Table 3: Types of pathologies detected in the cases of study

\begin{tabular}{|l|c|c|}
\hline Pathology & Frequency & percentage \\
\hline Inflammatory Disease & 16 & 32 \\
\hline Infertility & 2 & 4 \\
\hline Congenital Lesions & 5 & 10 \\
\hline Trauma & 2 & 4 \\
\hline Swelling & 17 & 34 \\
\hline Neoplastic & 2 & 4 \\
\hline Others & 6 & 12 \\
\hline
\end{tabular}

In our study, out of $n=50$ cases, $n=16$ cases were detected to have inflammatory scrotalpathology on highfrequency US and Doppler study. Chronic Epididymo orchitis was the commonest inflammatory pathology detected, noted in $n=5$ cases. Next, the most frequentinflammatory pathology detected was acute Epididymo orchitis, noted in $n=4$ cases.

Table4:High-resolution US appearance of inflammatory scrotal pathology

\begin{tabular}{|c|c|c|c|c|c|}
\hline Echo pattern & $\begin{array}{c}\text { Acute } \\
\text { epididymitis }\end{array}$ & $\begin{array}{l}\text { Acute } \\
\text { Orchitis }\end{array}$ & $\begin{array}{l}\text { Acute Epididymo- } \\
\text { orchitis }\end{array}$ & $\begin{array}{l}\text { Chronic } \\
\text { epididymitis }\end{array}$ & $\begin{array}{c}\text { Chronic Epididymo- } \\
\text { orchitis }\end{array}$ \\
\hline Hyper echoic & & & & 1 & \\
\hline Hypo echoic & 2 & 1 & 2 & & \\
\hline Iso echoic & 1 & & 1 & & \\
\hline Heterogeneous & & & 1 & 1 & 2 \\
\hline Complex cystic & & & & & 1 \\
\hline \multicolumn{6}{|l|}{ Purely cystic } \\
\hline Epididymal calcification & & & & 1 & 1 \\
\hline Testicular calcification & & & & & 1 \\
\hline
\end{tabular}

Table 5:Color Doppler Appearance of Inflammatory ScrotalPathology

\begin{tabular}{|l|c|c|c|c|c|}
\hline $\begin{array}{l}\text { Color-Doppler } \\
\text { appearance }\end{array}$ & $\begin{array}{c}\text { Acute } \\
\text { epididymitis }\end{array}$ & $\begin{array}{c}\text { Acute } \\
\text { Orchitis }\end{array}$ & $\begin{array}{c}\text { Acute Epididymo- } \\
\text { orchitis }\end{array}$ & $\begin{array}{c}\text { Chronic } \\
\text { epididymitis }\end{array}$ & $\begin{array}{c}\text { Chronic Epididymo- } \\
\text { orchitis }\end{array}$ \\
\hline Focal increase in Vascularity & & & 1 & 2 & 2 \\
\hline Diffuseincrease in Vascularity & 2 & 1 & 3 & 1 & 2 \\
\hline The focal decrease in Vascularity & & & & & 1 \\
\hline The diffuse decrease in Vascularity & & & & & \\
\hline
\end{tabular}


Heterogenous signals with areas of necrosis were seen in $n=2$ cases. The homogenous signal was noted in $n=1$ of $n=2$

cases. Hemorrhage and Capsule were noted in $n=1$ of $n=3$ cases. Septations were seen $n=1$ of $n=2$ cases (table 6 )

Table 6: MRI Evaluation of Testicular Masses

\begin{tabular}{|c|c|c|c|c|c|c|c|}
\hline $\begin{array}{c}\text { Sl. } \\
\text { No }\end{array}$ & $\begin{array}{c}\text { Signal } \\
\text { homogeneity }\end{array}$ & $\begin{array}{c}\text { Low } \\
\text { signal }\end{array}$ & Necrosis & Hemorrhage & Capsule & Septae & $\begin{array}{c}\text { Histopathological } \\
\text { diagnosis }\end{array}$ \\
\hline 1 & Absent & Absent & Present & Present & Present & Absent & $\begin{array}{c}\text { Immature teratoma with } \\
\text { malignant transformation of } \\
\text { left Testis. }\end{array}$ \\
\hline 2 & Present & Present & Absent & Absent & Absent & Present & Seminoma of right Testis \\
\hline
\end{tabular}

\section{Discussion}

The superficial location of the scrotal contents makes them ideally suited for sonographic examination. The development of high-frequency, real-time scanners has enhanced the diagnostic accuracy of scrotal sonographic examinations. Scrotal ultrasound has reached a level of maturity that allows the technique to be the first and only imaging examination necessary to evaluate the scrotal contents. In this study, out of $n=50$ cases, $n=16$ cases were detected to have inflammatory scrotal pathology on highfrequency US and Doppler study. Chronic Epididymo orchitis was the commonest inflammatory pathology detected, noted in $n=5$ cases. Next, the most frequent inflammatory pathology detected was acute Epididymo orchitis, noted in $\mathrm{n}=4$ cases. $\mathrm{PH}$ Arger et al; ${ }^{[4]}$ in a series of 62 patients, detected the following pathologies: Inflammatory diseases in 16 cases (26\%), and noninflammatory swellings in 45 cases (67\%).Wilcher et al; ${ }^{[5]}$ in a study of 43 pts (86 testes), noted the following distribution of pathologies: Inflammatory diseases 12 cases, Noninflammatory diseases in 28 cases. Richie et al; ${ }^{[6]}$ in their study of 124 patients (243 testicles) by ultrasonography, found inflammatory lesions in 31 cases, and non-inflammatory swellings in 75 cases. Horstman et al; ${ }^{[7]}$ in their study of 45 patients, found acute epididymitis present in 25 cases (56\%), acute Epididymo-orchitis in 19 cases (42\%), acute orchitis in 1 case ( $2 \%)$. No case of chronic Epididymo orchitis was reported.Lerner et al; ${ }^{[8]}$ in their limited series of 5 cases of acute inflammatory diseases of the scrotum, found acute epididymitis in 3 patients (60\%), acute Epididymo orchitis in 2 patients (40\%). Farriol et al; ${ }^{[9]}$ in their study of 25 cases of acute inflammatory diseases of scrotum using high-resolution grey scale and power Doppler sonographic study, found epididymitis in 11 cases (44\%), Epididymo-orchitis in 10 cases (40\%), orchitis in 2 cases ( $8 \%$ ), funiculitis in 2 cases ( $8 \%)$. Of $n=3$ cases of acute epididymitis, we observed diffuse hypoechogenicity with a diffuse increase in vascularity, and the size of epididymis was increased in $n=2$ cases. These findings are similar to the findings of Horstman et al; ${ }^{[10]}$ in their study of 45 cases found $70 \%$ hypoechoic and $30 \%$ isoechoic presentation. Farriol et al; ${ }^{[9]}$ in their study of 11 cases $n=9$ cases with a hypoechoic presentation of acute epididymitis.The $n=2$ cases of neoplastic swellings were germ cell tumors, one of which was histopathologically confirmed to be seminoma. These findings are in a similarity to previous studies by Grantham et al; ${ }^{[11]}$ and Schwerk et al; ${ }^{[12]}$ Seminoma case showed well-defined hypoechoic mass involving right Testis. It showedincreased vascularity on the color Doppler study. CT scan showed $n=2$ cases of metastasis.One had distant metastasis to the lungs, liver, and retroperitoneum. One of them had shown a metastatic deposit in the bifurcation of left iliac vessels.

\section{Conclusion}

Within the limitations of the present study, we can conclude that ultrasonography is best for the demonstration of morphological changes due to acute scrotal inflammation. The color doppler sonography can accurately differentiate between testicular ischemia and torsion from acute inflammatory diseases. High-frequency ultrasonography with Doppler is highly sensitive in demonstrating the varicoceles. MRI provides better delineation of borders, cystic components, and tissue signal intensities of the testicular masses. Thus, useful for further characterization of testicular masses. CT is the imaging modality of choice for detecting metastatic deposits

\section{REFERENCES}

1. Coley BD. Sonography of pediatric scrotal swelling. Semin Ultrasound CT MR 2007;28(1):297-306.

2. Raj SMD, Ramakrishna Y, Aithal K. Role of high-frequency ultrasound and color Doppler in the evaluationof scrotal pathologies. J. Evolution Med. Dent. Sci. 2017;6(11):862866,

3. Rizvi SA, Ahmad I, Siddiqui MA, Zaheer S, Ahmad K. Role of color Doppler ultrasonography in the evaluation of scrotal swellings: pattern of disease in 120 patients with review of the literature. Urol J 2011;8(5):60-65. 
4. Peter H Arger, CB Mulhern Jr, BG Coleman, et al, Prospective analysis of the value of Scrotal Ultrasound.Radiology1981; 141: 763-766

5. Max K Willscher Conway JF Jr, Daly KJ, DiGiacinto TM, Patten $D$ et al. Scrotal Ultrasonography.The Journal of Urology1983; 130:931 - 935

6. Robert M Weiss, AR Carter, AT Rosenfield. High-resolution Real-time Ultrasonography in the Localization of the Undescended Testis, The Journal of Urology, 1986; 135:936-938

7. William G Horstman, William D Middleton, G Leland Melson, Scrotal inflammatory disease: color Doppler US findings, Radiology1991;179:55-59.

8. Robert M Lerner, RA Mevorach, WC Hulbert R Rabinowitz. Color Doppler US in theevaluation of Acute ScrotalDisease, Radiology, 1990; 176:355-358.

9. Victoria Garriga Farriol, Xavier PC, Elina Gallardo A, et al. Gray-scale and power Doppler sonographic appearances of acute inflammatory diseases of the scrotum.J ofClin Ultrasound 2000;28: 67-72.

10. Horstman W G, Scrotal inflammatory disease-color Doppler evaluation. Radiology1991; 179:55-59.

11. Grantham G, Testicular neoplasms. Radiology, 1985; 157:775-780

12. Wolf B Schwerk, WN Schwerk, G Rodeck, et al. Testicular tumors: Prospective analysis of real-time US pattern and abdominal staging, Radiology; 164: 369-374.

How to cite this article : Thakur HD Singh, P Keerthi Bharati . A Comparative Study of Scrotal Pathologies by Ultrasound and Their Correlation with CT and MRI.Perspectives in Medical Research 2021; 9 (1):54-58

DOI:10.47799/pimr.0901.11

Sources of Support: Nil, Conflict of interest: None declared 